\title{
A especialização em bioética da Universidade de Brasília: estudo de caso das quinze primeiras edições
}

\section{The specialization in bioethics at the University of Brasilia: a case study of the first fifteen editions}

\author{
Fabiano Maluf \\ Cátedra Unesco / Programa de Pós-Graduação em Bioética da UnB, Brasília, \\ Brasil \\ maluffabiano@gmail.com \\ Camilo Hernan Manchola Castillo \\ Cátedra Unesco / Programa de Pós-Graduação em Bioética da UnB, Brasília, \\ Brasil \\ camilomanchola@gmail.com

\section{Volnei Garrafa} \\ Cátedra Unesco / Programa de Pós-Graduação em Bioética da UnB, Brasília, \\ Brasil \\ garrafavolnei@gmail.com
}

Resumo: O presente artigo tem como objetivo realizar um resgate histórico das quinze edições do curso de especialização em bioética da Universidade de Brasília, descrevendo e analisando criticamente a estrutura bem como os conteúdos programáticos abordados, o perfil e número de alunos e os temas trabalhados nas monografias. O curso tem como característica principal trabalhar uma bioética crítica, politizada e socialmente engajada, em oposição a uma bioética horizontalizada, meramente descritiva e neutral. Ao adotar e incorporar os princípios da Declaração Universal sobre Bioética e Direitos Humanos por meio da prescrição contida no Core Curriculum da Unesco, o curso não se restringe a analisar somente as questões sanitárias e educacionais, a interpretar as questões epidemiológicas e ambientais, mas propor e desenvolver mecanismos de intervenção capazes de definir novas frentes de pesquisa no campo biotecnocientífico, na formação de pessoal e no papel do Estado na proteção de seus cidadãos, principalmente os mais vulneráveis.

Palavras chave: ensino da bioética, educação em bioética, formação profissional.

\footnotetext{
Abstract: This article aims to conduct a historical review of the fifteen editions of the specialization on bioethics at the University of Brasilia describing and critically analyzing its structure and syllabus, the profile and number of students, and the themes discussed in the final papers. The course presents
} 
a critical, politicized and socially engaged bioethics that opposes to a merely descriptive and neutral vision of this field. By adopting and incorporating the principles of UNESCO's Universal Declaration on Bioethics and Human Rights contained in the UNESCO's Core Curriculum, the course is not restricted to the analysis of health and educational issues, or to the interpretation of epidemiological and environmental issues, but to the proposal and development of intervention mechanisms that are able to define new research lines in the biotechnoscientific field, in the professional training and in the state's role in protecting its citizens, especially the most vulnerable.

Keywords: teaching in bioethics, education in bioethics, professional training.

\section{Introdução}

A bioética, como disciplina autônoma, tem despontado nas estruturas convencionais da educação, conquistando progressivamente espaço junto às universidades e instituições, nas mais distintas áreas e carreiras profissionais, contribuindo para a mediação, o diálogo e a tolerância no debate dos problemas éticos vivenciados atualmente.

Interpretada por Garrafa como tardia (1), a bioética brasileira, já nos seus primórdios, na década de 1990, se direcionava majoritariamente na busca de uma reflexão autóctone, voltada à dimensão social e em consonância com os dilemas vivenciados no campo da saúde pública.

Considerando a dimensão acadêmica, a publicação dos livros $A$ dimensão da ética em saúde pública de autoria de Volnei Garrafa, editado pela Faculdade de Saúde Pública da Universidade de São Paulo e Kellogg Foundation em 1995, e A terceira margem da saúde de Fermin Roland Schramm, editado pela Universidade de Brasília em 1996, pode ser considerada o marco inicial da reflexão bioética brasileira (2).

De acordo com Gomes e cols. (2), o desenvolvimento mais orgânico do ensino e da pesquisa em bioética também teve início nesse período, mais precisamente em 1994, quando se criou o Núcleo de Estudos e Pesquisa em Bioética (NEPeB), vinculado ao Centro de Estudos Avançados Multidisciplinares (CEAM) e ao Departamento de Saúde Coletiva (DSC) da Faculdade de Ciências da Saúde, ambos na Universidade de Brasília (UnB). Nos três primeiros 
anos da fase de implantação, o NEPeB atuou como instância de divulgação da bioética no âmbito universitário institucional (2). Já nos seus primórdios se direcionava na busca de uma reflexão muito particular, voltada à dimensão social e em consonância com os dilemas vivenciados no campo da saúde pública.

Embora desde a década de 1990 algumas instituições já começassem a inserir a bioética como disciplina, somente a partir de 2001 as novas Diretrizes Curriculares Nacionais dos cursos de graduação na área da saúde (3-5) passaram a reconhecê-la dentre as novas competências e habilidades requeridas na formação dos profissionais de saúde.

Entretanto, apesar dos incentivos para introdução da bioética como disciplina regular nos currículos dos cursos de graduação e de quase duas décadas de atividade acadêmica, ainda são escassos os textos e estudos sobre o processo histórico de seu ensino no Brasil (6), assim como se percebe forte resistência para o abandono das raízes deontológicas tradicionais $(7,8)$.

Nesse sentido, o presente artigo tem como objetivo realizar um resgate histórico das quinze edições do curso de especialização em bioética da Universidade de Brasília (UnB), o curso mais tradicional do país oferecido regularmente desde 1998, descrevendo e analisando criticamente a estrutura, bem como os conteúdos programáticos abordados, o perfil e número de alunos e os temas trabalhados nas monografias.

\section{Antecedentes}

O rápido e extraordinário avanço tecnocientífico observado nas últimas décadas, roubou do homem o tempo necessário para uma reflexão mais prudente sobre as consequências que suas ações podem provocar na sociedade e meio ambiente $(9,10)$. Como resposta para vencer o preconceito de que nas universidades só se deva discutir tecnociência (11), iniciativas surgem como alternativas para definitivamente incorporar e efetivar o discurso bioético na prática profissional. Nesse contexto, o ensino da bioética, por meio de cursos de especialização, desponta como alternativa para preencher esta carência ética, e resgatar e aprofundar valores antes pouco trabalhados na graduação. 
Poucos estudos estenderam a pesquisa em bioética às demais áreas acadêmicas: a maioria ficou direcionada ao ensino e avaliação da ética deontológica clássica nos cursos de graduação (12), outros direcionam suas atividades ao campo da medicina legal, sendo raros os esforços no sentido de mapear a realidade do ensino no contexto dos cursos de pós-graduação em bioética no Brasil.

O NEPeB iniciou suas atividades no campo do ensino de graduação regular com o oferecimento da disciplina "Introdução à Bioética" (2 créditos - 30 horas/aula-semestre) para todas as carreiras acadêmicas da UnB e da disciplina "Bioética" (4 créditos), obrigatória para o curso de odontologia. Logo depois, em 1995, com a criação do Programa de Pós-graduação stricto sensu em Ciências da Saúde, o Núcleo começou a oferecer regularmente a disciplina "Bioética" em nível de mestrado e doutorado (4 créditos), com área de concentração específica no tema. Concomitantemente, o NEPeB começou a desenvolver pesquisas científicas direcionadas à área de bioética, com expressivo número de publicações na época.

Imediatamente após sua criação, o NEPeB foi o primeiro núcleo de bioética no Brasil reconhecido formalmente como "Grupo Consolidado de Pesquisa" junto ao Conselho Nacional de Desenvolvimento Científico e Tecnológico (CNPq), situação mantida até hoje. A estreita ligação com o Núcleo de Estudos em Saúde Pública (NESP), também vinculado ao CEAM e ao DSC, permitiu e estimulou relacionar o campo multi-inter-transdisciplinar da bioética à área da saúde pública.

É importante considerar tal aspecto, pois estas instâncias - o DSC, NESP e NEPeB - congregaram docentes e pesquisadores com participação e envolvimento acadêmico especiais no Movimento da Reforma Sanitária brasileira e na construção do Sistema Único de Saúde, bem como disposição para atuar na área dos direitos humanos.

O referido Núcleo (NEPeB) possui uma trajetória de luta por uma bioética crítica, que leva em conta o contexto no qual estão inseridos os principais problemas que afligem tanto o Brasil como a região latino-americana, ou seja, a exclusão social, as diferentes formas de discriminação, a escassez de recursos públicos.

Assim, essa bioética crítica prioriza o coletivo, o "nós", e 
contempla na discussão valores como a solidariedade, a cooperação, o respeito à diversidade cultural e ao pluralismo moral, os direitos humanos, a responsabilidade social e a equidade, características mais próximas do nosso dia a dia, incipientes e pouco trabalhadas pela bioética brasileira daquela época, que apenas abordava a perspectiva anglo-americana, hegemonicamente principialista, acentuadamente individualista e voltada preferencialmente aos microproblemas (21), e que tinha como característica principal a supervalorização do princípio da autonomia.

É oportuno ressaltar que o surgimento dessa bioética crítica, foi acompanhado pelo nascimento de uma corrente marcadamente diferenciada do principialismo, que a partir dos anos 1990, reclamou a incorporação na bioética do estudo dos problemas persistentes - sociais e ambientais, considerados em sua essência, como condicionantes básicos de saúde (22) - e do princípio da justiça, deixado de lado devido à supervalorização da autonomia pelo principialismo. Essa corrente também encontrou eco na perspectiva europeia que teve como linha de atuação o enfoque personalista cuja preocupação recaía sobre a dimensão social do homem, com atenção aos interesses morais coletivos (macroproblemas) e com forte predomínio do princípio da justiça $(11,21)$.

Assim, contrapondo-se ao modelo hegemônico estabelecido, os países periféricos, através da sua aproximação crítica da bioética, se fizeram valer dos espaços e meios necessários para incluir temas antes pouco discutidos na bioética. A América Latina foi responsável direta por grande parte dessa transformação ao inserir na pauta bioética mundial questões políticas a serem melhor trabalhadas e resolvidas.

No Brasil, os centros de investigação mais importantes em termos de produção acadêmica começaram a buscar caminhos próprios para lidar com os temas e conflitos bioéticos identificados no país (22). Assim, novas propostas epistemológicas surgiram como alternativas ao principialismo e demais correntes teóricas mais tradicionais como, por exemplo: a Bioética de Intervenção, a Bioética de Proteção e a Bioética da Teologia da Libertação (24).

A Bioética de Intervenção (BI) tem fundamentação filosófica utilitarista, consequencialista e solidária, defendendo como 
moralmente justificável, entre outros aspectos, no campo público e coletivo, a prioridade com relação a políticas públicas e tomadas de decisão que resultem nas melhores consequências coletivas, pelo maior tempo possível, envolvendo o maior número de pessoas (25). Outros indicadores utilizados pela BI são o empoderamento, a libertação e a emancipação, dentro da proposta regional ampliada de substituição ou utilização mais adequada do princípio da autonomia, principalmente no sentido coletivo e societário $(23,26)$.

Então, a identidade dessa bioética crítica vem sendo construída e fortalecida como decorrência natural dos mais de vinte anos de atividades desenvolvidas pelo Núcleo através, por exemplo, das assessorias e apoio acadêmico-científico a órgãos públicos e entidades profissionais; da participação e organização de eventos e das relações de intercâmbio com organismos nacionais e internacionais.

A partir da exitosa experiência acima, em agosto de 1998, o NEPeB deu início à primeira turma do curso de pós-graduação lato sensu em bioética, com duração experimental de um ano e meio na sua primeira edição (agosto/98 - dezembro 1999 - 460 horas/ aula). Atualmente o curso está na sua $17^{a}$. edição anual e regular, com desenvolvimento de março a dezembro de cada ano, com um oferecimento de 30 vagas no cumprimento de 375 horas/aula.

É oportuno considerar as transformações ocorridas no Núcleo durante esse período, tanto nas características institucionais quanto naquelas relacionadas à própria formulação do conhecimento científico no campo da bioética, com reflexos significativos na produção acadêmica de monografias, dissertações e teses, muitos dos quais se transformaram em artigos científicos publicados em revistas indexadas.

No nível institucional, destaca-se o reconhecimento da Unesco para com as atividades desenvolvidas pelo NEPeB, conferindo-lhe o título de Cátedra em 2004 e, mais recentemente em 2008, a criação do Programa de Pós-graduação stricto sensu (mestrado e doutorado) em Bioética, pioneiro na oferta nas universidades públicas brasileiras (2).

No nível acadêmico, é por meio da Cátedra Unesco de Bioética da UnB que foi apresentada à comunidade acadêmica a Bioética de 
Intervenção, durante o Sexto Congresso Mundial de Bioética, em 2002, que recupera o ponto de partida da disciplina, de acordo com a base da proposta original de V.R. Potter: ampliar o âmbito de atuação da bioética para a dimensão social; ratificar a transdisciplinaridade como estratégia de abordagem bioética; e incorporar os direitos humanos como eixo orientador da ética na prática coletiva $(2,13,14)$.

A aprovação e homologação como Cátedra Unesco de Bioética, a partir de 2005, permitiu ampliar e consolidar a bioética ao campo da saúde pública como realidade palpável. Merece destaque a participação da Cátedra na construção da proposta brasileira para a elaboração da Declaração Universal sobre Bioética e Direitos Humanos (DUBDH) na defesa da inclusão de temas sociais, sanitários e ambientais e também a assinatura, logo a seguir, de um acordo de cooperação entre UnB e Unesco no sentido de desenvolvimento do Core Curriculum (CC) de Bioética proposto por aquele organismo internacional e fundamentado na referida Declaração.

Todo este processo de intensa atividade acadêmica refletiu no modo de estruturar e formatar o curso de especialização da UnB, conferindo-lhe uma identidade própria ao longo dos anos.

\section{Método}

Trata-se de um estudo documental de caráter exploratório, descritivo e retrospectivo. Foi realizado, no período compreendido entre setembro e dezembro de 2014, com levantamento e análise dos arquivos e registros das quinze edições até então já finalizadas dos cursos de especialização em bioética existentes na secretaria da Cátedra Unesco da Universidade de Brasília. Com base nisso, para o alcance dos objetivos propostos, realizou-se apuração do quantitativo bem como da área de formação, faixa etária e gênero dos alunos que compõem a amostra.

Com relação aos temas desenvolvidos nas monografias de conclusão de curso, será tomado como referência o modelo simplificado de campos de estudo e linhas de pesquisa (três no total) e temas (dez no total) adotado no Programa stricto sensu (mestrado e doutorado) em Bioética da UnB, descrito a seguir: 
- Fundamentos de Bioética e Saúde Pública: (Bases Epistemológicas da Bioética; Bioética e Direitos Humanos; Bioética e Pluralismo Histórico; Ética Aplicada e Bioética);

- Situações Emergentes em Bioética e Saude Pública: (Ética em pesquisas com seres humanos; Ética e Biotecnociência; Bioética Ambiental e Proteção Animal);

- Situações Persistentes em Bioética e Saude Pública: (Bioética Social; Bioética Clínica; Bioética e Atenção à Saúdel).

Para a concretização desta etapa, buscou-se a leitura do título e do resumo das monografias e trabalhos científicos, com o intuito de comprovar as informações desejadas. Para o armazenamento dos dados foi utilizado o Excel ${ }^{\circledR}$ e os resultados serão descritos por meio de frequência absoluta e frequência relativa.

Quanto aos aspectos éticos, o presente trabalho, de abordagem quantitativa, teve como instrumento a base de dados da Cátedra Unesco de Bioética da UnB, da qual se extraíram as informações necessárias, portanto não sendo exigida a apreciação por um Comitê de Ética em Pesquisa (CEP).

\section{Resultados e discussão}

O universo deste estudo se constituiu das quinze edições do curso de especialização em bioética realizadas no período compreendido entre 1998 a 2013. É importante ratificar que a primeira edição teve início no segundo semestre de 1998 e conclusão no final de 1999. A partir de 2000, os cursos tiveram desenvolvimento anual, iniciando em março e terminando em dezembro do mesmo ano.

Ininterruptamente, desde sua criação, o curso de especialização em bioética da UnB preservou seu espírito laico, democrático, transdisciplinar e de respeito ao pluralismo moral, características fundamentadas pelo estatuto epistemológico da bioética.

Durante o período analisado, 467 alunos iniciaram o curso, sendo que 58 alunos (12\%) não concluíram, abandonando ou desistindo o curso por diferentes motivos, índice excelente comparativamente a outros cursos da mesma modalidade (especialização). Assim, 409 
alunos (88\%) concluíram o curso e obtiveram o título de especialista em bioética. Os dados apresentados confirmam os baixos índices de desistência já apresentados em 2012 em publicação oficial da Unesco (15).

Foi constatado que da amostra de 409 alunos concluintes, 128 alunos (31\%) pertenciam ao gênero masculino e 281 (69\%) ao gênero feminino, ou seja, houve pouco mais de $2 / 3$ pertencentes ao gênero feminino. Gomes e cols. (2), ao realizarem uma análise da primeira década do curso de especialização oferecido pela Cátedra Unesco de Bioética da UnB, contabilizaram um total de 292 alunos nas dez edições concluídas até o final de 2007. Desse total, 264 estudantes concluíram o curso sendo que 196 eram do gênero feminino e 96 eram do gênero masculino. Estes dados corroboram os números encontrados por Vidal em 2010 (16) no Programa de Educação Permanente em Bioética da Redbioética da Unesco, no qual 62\% dos alunos eram do gênero feminino e 38\% do gênero masculino.

Quanto à distribuição dos alunos por profissões dentre as carreiras encontradas durante as quinze edições, constata-se a predominância da área de saúde, com destaque para Medicina e Enfermagem, com $11,98 \%$ e $11 \%$, respectivamente. Outras carreiras dessa área incluem Odontologia, Farmácia e Fisioterapia, com $8,80 \%, 6,60 \%, 2,69 \%$, respectivamente.

Chama a atenção a presença de carreiras de outras áreas, diferentes da área da saúde, como Direito, Biologia, Comunicação, Psicologia, Administração de Empresas, Serviço Social, Filosofia, Ciências Sociais, Medicina Veterinária e Pedagogia, com 10,02\%, $9,05 \%, 6,11 \%, 3,91 \%, 3,91 \%, 3,18 \%, 2,69 \%, 1,96 \%, 1,47$ e $1,47 \%$, respectivamente.

Ressalta-se que num item a parte, chamado de "Outras licenciaturas", foram encontradas outras vinte e oito áreas de atuação $(15,16 \%)$ perfazendo um total de nada menos que quarenta e três carreiras no universo das quinze edições estudadas, reforçando o caráter multi e interdisciplinar da bioética. Os resultados apontam estrita semelhança, outra vez, com os dados encontrados por Vidal ao identificar a distribuição dos alunos por profissões no Programa de Educação Permanente em Bioética da Redbioética da Unesco em 2010 (16). 
Embora os resultados encontrados constatem o forte predomínio da área da saúde nos cursos de especialização em bioética, não se pode desprezar o interesse crescente das demais carreiras, especialmente a área das ciências humanas. Gradativamente, a procura e o interesse por cursos desta natureza têm crescido (17), e isso pode ser atribuído ao amplo campo de inserção da bioética que inclui, além dos dilemas biomédicos, "a discussão dos temas de direitos humanos e cidadania, questões ambientais sobre desenvolvimento sustentável e preservação da biodiversidade, poluição ambiental e discriminação social" (7) (p. 511).

A bioética pode ser considerada como conhecimento aplicável a todas as profissões, especialmente às da área da saúde e, dessa forma, é atribuída fundamental importância à utilização de seus referenciais teóricos e práticos para uma atuação profissional consciente e crítica (18). Segundo Barchifontaine (17), "os cursos de pós-graduação têm por objetivo fomentar o desenvolvimento e o aperfeiçoamento profissional, constituindo-se como um momento essencial de formação, em todas as áreas profissionais" (p. 399).

Quanto à distribuição dos alunos por faixa etária, observase o predomínio de alunos entre 31 e 40 anos de idade, e quanto à distribuição dos alunos por tempo de formado, evidencia-se o predomínio de profissionais na faixa compreendida entre 1 e 5 anos de formado. Infere-se daí a carência e a pouca ênfase dada aos conteúdos de bioética durante a graduação, ensejando por parte dos profissionais a necessidade de conhecimento e aprofundamento no tema.

De fato, Matos e Tenório (11) afirmam que "a dimensão ética, evidenciada durante a graduação, parece ficar comprometida quando as determinações econômicas passam a fazer parte da complexidade que envolve a atenção profissional" (p.3262). Embora não se trate de responsabilizar exclusivamente a universidade pelas carências dos estudantes na graduação (12) - uma vez que o papel da escola na formação ética dos profissionais é limitado, porque esses valores também nascem da experiência pessoal de cada um, sobretudo no âmbito familiar (11) - deve-se ressaltar que a escola tem como função intervir para a construção de uma consciência ética que transforme o educando em cidadão (9). Como alternativa para preencher esta 
carência ética existem os cursos de pós-graduação lato sensu - as especializações - em bioética, seja devido à metodologia de ensino utilizada ou à pequena carga horária dispensada à disciplina na graduação.

É oportuno destacar, neste momento, as transformações relatadas nas avaliações feitas pelos estudantes por ocasião da conclusão do curso de especialização em bioética da Cátedra Unesco da UnB em pesquisa realizada por Gomes e cols. (2) em 2007. Para 94,45\% dos estudantes o contato com a bioética trouxe conhecimento que foi agregado à dimensão profissional na utilização nos princípios e conceitos da área, e para 80,55\% a influência da bioética se estendeu à vida cotidiana proporcionando reflexões para o dia-adia, norteadas por parâmetros éticos na dimensão social, tornandoas pessoas mais preocupadas em fazer a ponte entre teoria e prática.

Desse modo, é possível inferir que a bioética vem sendo percebida pelos participantes dos cursos de especialização da UnB como uma ferramenta que propicia transformação tanto na vida profissional quanto na vida pessoal dos participantes, o que remete à sua característica intrínseca, ou seja, o fato desta ser uma ética aplicada (2).

Prado e Garrafa (18), em estudo realizado com o objetivo de analisar se o ensino da bioética, como disciplina de reflexão, representa um diferencial atitudinal na formação em odontologia, concluíram que a incorporação dos fundamentos teóricos e práticos da bioética é de fundamental importância para a formação desse profissional de saúde por favorecer a compreensão da realidade numa perspectiva consciente, crítica e interdisciplinar.

Quanto à definição dos objetivos do ensino da bioética na pósgraduação, o primeiro desafio seria como transmitir conhecimento a partir de uma visão inter e transdisciplinar, modificando atitudes e formando novos valores (19).

Provavelmente o grande dilema pedagógico para a bioética como disciplina seja a construção de seus conteúdos: como deve ser estruturada, como ela é definida em termos de domínio das concepções teóricas e seus objetivos. Tais dilemas podem ser considerados como os principais desafios a serem ultrapassados, sobretudo porque a bioética não é uma disciplina definitiva e 
consolidada, nem nos seus conteúdos, nem nos seus limites teóricos, e muito menos com relação às metodologias utilizadas no seu processo de ensino-aprendizagem.

Torna-se, então, um desafio elaborar uma ementa de ensino para a bioética que contemple a multiplicidade de disciplinas envolvidas, haja vista a crescente incorporação de novidades tecnológicas com implicações morais que acontecem diariamente na vida das pessoas (20).

A estrutura básica dos cursos oferecidos pela Cátedra Unesco de Bioética da UnB tem como característica sua distribuição em módulos dispostos sequencialmente, de modo a contemplar os principais temas e abordagens discutidas em bioética. A carga horária é de 375 horas-aula (25 créditos) as quais estão assim distribuídas:

- Módulo I: Introdução à Bioética - 15 horas-aula (01 crédito);

- Módulo II: Filosofia Básica - 30 horas-aula (02 créditos);

- Módulo III: Fundamentos da Bioética - 90 horas-aula (06 créditos);

- Módulo IV: Bioética Clínica e Ética em Pesquisa - 60 horasaula (04 créditos);

- Módulo V: Metodologia de Pesquisa - 45 horas-aula (03 créditos);

- Módulo VI: Bioética das Situações Emergentes - 75 horas-aula (05 créditos);

- Módulo VII: Bioética das Situações Persistentes - 60 horasaula (04 créditos);

- Módulo VIII: Trabalho de Conclusão do Curso (TCC).

Quanto à distribuição das monografias realizadas no período estudado, é oportuno ressaltar que até 2007 as monografias eram realizadas através da modalidade de trabalhos de pesquisa aplicada por grupos de até três alunos, sendo que a partir de 2008 passaram a ser desenvolvidas individualmente. Nesse contexto, observou-se que o tema "Ética aplicada e Bioética" foi o mais desenvolvido, com 26,95\% dos 256 textos encontrados, demonstrando assim que foi bastante explorada a reflexão e problematização de valores morais aplicados a práticas sociais específicas com ênfase na tomada de decisão ética e resolução de conflitos. 
A esse tema seguiram "Bases epistemológicas da bioética", "Bioética Clínica", "Bioética e Atenção à Saúde", "Ética e Biotecnociência", "Ética em pesquisa", "Bioética ambiental e Proteção animal", "Bioética e Direitos Humanos" e "Bioética e Pluralismo Moral", com 13,67\%, 12,50\%, 10,94\%, 8,20\%, 7,81\%, $7,03 \%, 4,69 \%$ e $4,69 \%$, respectivamente. Por outro lado, observou-se a incipiente procura pela temática da "Bioética Social", com 3,52\%. Tal situação pode estar relacionada ao fato da ainda recente difusão da Declaração Universal de Bioética sobre Direitos Humanos, promulgada em outubro de 2005, tendo seus princípios utilizados como referencial teórico.

A partir desses dados, pode-se depreender que a estrutura e organização do ensino da bioética devem ser preferencialmente elaboradas de acordo com os conteúdos temáticos definidos segundo o contexto sócio-cultural da localidade onde esteja instalado o curso, amparadas por marcos conceituais e valendo-se de um conjunto harmônico e científico de metodologias.

Exemplificando, enquanto "em países do primeiro mundo, o ensino da bioética está voltado, principalmente, para os problemas éticos gerados pela aplicação de novas biotecnologias, no Brasil, os problemas bioéticos têm maior amplitude" (21) (p.128-9). Assim, no caso do Brasil o enfoque deve ir além do principialismo individualista e especialmente focado no princípio da autonomia, e estar direcionado especialmente às diversas questões sociais, econômicas, ambientais e de saúde pública, lembrando as particularidades da bioética crítica, especificamente as Bioéticas de Intervenção,da Bioetica de Proteção e da Bioética da Teologia da Libertação, que foram mencionadas antes.

E é nesse aspecto que reside o principal diferencial do curso de especialização da UnB que, embora também faça menção ao principialismo, reservando-lhe duas aulas específicas no módulo "Fundamentos de Bioética", tem como característica a adoção da DUBDH como referencial teórico do curso em suas últimas edições especialmente o capítulo referente aos seus 15 "princípios", que vão do artigo 3 ao 17 - e do Core Curriculum da Unesco (27).

Os artigos da DUBDH trabalhados no curso de especialização da UnB, tendo como base o Core Curriculum, situam o conhecimento da 
bioética dentro da realidade concreta, abrindo novas perspectivas mais amplas no sentido biopsicosocial - para reflexão e ações da disciplina.

Ao associar a bioética como campo normativo particular na atenção e cuidado da vida e da saúde, com os Direitos Humanos como campo normativo universal básico de obrigações morais e jurídicas para todas as formas de vida no planeta, identificam-se os valores fundamentais de uma ética universal pautada no respeito à dignidade humana, na luta pela igualdade de direitos, na liberdade, na justiça, fraternidade e paz (28).

\section{Considerações finais}

O embasamento ético atualmente tão exigido para uma boa prática profissional clínico-assistencial e também afetivo-atitudinal, estimula a busca por novas formas de abordagens da realidade como, por exemplo, as reflexões éticas. Desse modo, a formação em bioética, por meio de cursos de especialização, deve ser entendida como parte de um processo mais abrangente e completo de construção da atuação profissional, a partir do aprimoramento da dimensão ética e do desenvolvimento de valores e compromissos com bases mais sólidas do que apenas o desejo e a intuição.

O curso de especialização em bioética da Universidade de Brasília tem como característica principal trabalhar uma bioética crítica, politizada e socialmente engajada em oposição a uma bioética horizontalizada, asséptica, meramente descritiva, neutral e distanciada da realidade concreta onde os problemas acontecem e necessitam ser enfrentados. É importante que novos caminhos sejam trilhados, mais amplos e comprometidos, capazes de enfrentar os macroproblemas bioéticos com os quais se deparam cotidianamente as nações periféricas do mundo e suas próprias instituições e profissionais, sobretudo da América Latina e do Caribe.

Ao adotar e incorporar os princípios da Declaração Universal sobre Bioética e Direitos Humanos como referencial teórico por meio da prescrição contida no Core Curriculum, o curso de especialização oferecido pela Cátedra Unesco de Bioética da Universidade de Brasília não se restringe a analisar somente as 
questões sanitárias e educacionais ou a interpretar as questões epidemiológicas e ambientais, mas propõe e desenvolve mecanismos de intervenção capazes de definir novas frentes de pesquisa no campo biotecnocientífico, na formação de pessoal e no papel do Estado na proteção de seus cidadãos, principalmente os mais vulneráveis.

Nesse sentido, o curso de especialização da UnB tem possibilitado aos profissionais de diferentes áreas uma formação cujo objetivo é proporcionar uma ampliação conceitual dos referenciais da bioética, aprofundando e reconstruindo conhecimentos a partir da realidade dos macroproblemas majoritários - sociais, sanitários e ambientais encontrados no Brasil e na América Latina.

\section{Referências}

1. Garrafa V. Radiografia bioética de um país-Brasil. Acta Bioethica. 2000; 4(1):171-73.

2. Gomes ASO, Rodrigues DLN, Sertão VS, Porto D. Ensino em bioética: breve análise da primeira década do Curso de Especialização da Cátedra Unesco de Bioétiva da UnB. Rev Bras Bioética 2009; 5(1-4):82105.

3. Figueiredo AM, Garrafa V, Portillo JAC. Ensino da bioética na área das ciências da saúde no Brasil: estudo de revisão sistemática. INTERthesis 2008; 4(2):47-72.

4. Ferreira HM, Ramos LH. Diretrizes curriculares para o ensino da ética na graduação em enfermagem. Acta Paul Enferm 2006; 19(3): 328-31.

5. Brasil. Conselho Nacional de Educação. Câmara de Educação Superior. Resolução no 4/2001. Diário Oficial da União. Brasília, 9 de novembro de 2001. Seção 1, p.38.

6. Oliveira GB, Guaiumi TJ, Cipullo JP. Avaliação do ensino de bioética nas faculdades de medicina do Estado de São Paulo. Arq Ciênc Saúde 2008; 15(3): 125-31.

7. Dantas F, Sousa EG. Ensino da deontologia, ética médica e bioética nas escolas médicas brasileiras: uma revisão sistemática. Rev Bras Educ Med 2008; 32(4): 507-17

8. Siqueira JE. Educação em bioética no curso de medicina. O Mundo da Saúde 2005; 29(3): 402-10.

9. Pires J, Garrafa V. Educação: nova fronteira da bioética. Ciência \& Saúde Coletiva 2011; 16(supl. 1): 735-45.

10. Finkler M, Caetano JC, Ramos FRS. A dimensão ética da formação profissional em saúde: estudo de caso com cursos de graduação em odontologia. Ciência \& Saúde Coletiva 201; 16(11):4481-92.

11. Matos MS, Tenório R. Percepção de alunos, professores e usuários acerca da dimensão ética na formação de graduandos de odontologia. Ciência \& Saúde Coletiva 2010; 15 (supl. 2): 3255-64.

12. Finkler M, Verdi MIM, Caetano JC, Ramos FRS. Formação profissional 
ética: um compromisso a partir das diretrizes curriculares? Trab Educ Saúde 2011; 8(3): 449-62.

13. Garrafa V. Multi-inter-transdisciplinaridade, complexidade e totalidade concreta em bioética. In: Garrafa V, Kottow M, Saada A (orgs.). Bases conceituais da Bioética - enfoque latino-americano. São Paulo: Editora Gaia; 2006, p.73-85.

14. Garrafa V, Porto D. Intervention bioethics: a proposal for peripheral countries in a context of power and injustice. Bioethics 2003; 17(56):399-416.

15. Garrafa V. El Programa de posgrado en Bioética de la Universidad de Brasilia. In: Vidal S (ed.). La Educación en Bioética en América Latina y el Caribe: experiencias realizadas y desafíos futuros. Uruguay: Unesco; 2012, p.343-51.

16. Vidal S. Una propuesta educativa de bioética para América Latina. Programa de educación permanente en Bioética. Redbioética Unesco. In: Ruiz-Valdepeñas BH, Moya FB (Eds.). Educar en Bioética al profesional de Ciencias de la Salud. Una perspectiva internacional. Madrid: Fundación Tejerina; 2010, p.121-57.

17. Barchifontaine CP. Perspectivas da bioética na América Latina e o pioneirismo no ensino de bioética no Centro Universitário São Camilo, SP. O Mundo da Saude 2005; 29(3):392-401.

18. Prado MM, Garrafa V. A bioética na formação em Odontologia: importância para uma prática consciente e crítica. Comum Ciênc Saude 2006; 17(4): 263-74.

19. Correa FJL. Enseñar bioética: como transmitir conocimientos, actitudes y valores. Acta Bioethica 2008; 14(1):11-7.

20. Caramico HJ, Zaher VL, Rosito MMB. Ensino da bioética nas faculdades de medicina do Brasil. Bioethikos 2007; 1(1):76-90.

21. Azevedo EES. Ensino de bioética: um desafio transdisciplinar. Interface 1998; 2(2):127-37.

22. Bergel, SD. Responsabilidad social y salud. Rev Bras Bioética 2006; $2(4): 443-67$.

23. Garrafa V. La Bioética en Brasil: de aparición tardía pero bien encaminada. In: Vidal S (ed.). La Educación en Bioética en América Latina y el Caribe: experiencias realizadas y desafíos futuros. Uruguay: Unesco; 2012, p.179-94.

24. Oliveira AAS, Villapouca KC, Barroso W. Perspectivas epistemológicas da bioética brasileira a partir da teoria de Thomas Khun. Rev Bras Bioética 2005; 1(4): 363-85.

25. Tealdi JC. (Org.). Diccionario latinoamericano de Bioética. Bogotá: Unesco; Red Latinoamericana y del Caribe de Bioética, Universidad Nacional, 2008. p. 163.

26. Garrafa V. Inclusão social no contexto político da bioética. Rev Bras Bioética 2005; 1(2):122-32.

27. Garrafa V. O novo conceito de bioética. In: Garrafa V, Kottow $\mathrm{MH}$, Saada A (Orgs). Bases conceituais da bioética - enfoque latinoamericano. São Paulo: Gaia, 2006, p.9-15. 
Revista Brasileira de Bioética 2015;11 (1-4):98-114

28. Tealdi JC. Para una declaración universal de bioética y derechos humanos: una visión de América Latina. Rev Bras Bioética 2005; 1(1):7-17.

Recebido em: 23/05/2016 Aprovado em: 20/08/2015 